University of Windsor

Scholarship at UWindsor

OSSA Conference Archive

OSSA 6

Jun 1st, 9:00 AM - 5:00 PM

\title{
Warranting Arguments, the Virtue of Verb
}

James Francisca Klumpp

University of Maryland

Follow this and additional works at: https://scholar.uwindsor.ca/ossaarchive

Part of the Philosophy Commons

Klumpp, James Francisca, "Warranting Arguments, the Virtue of Verb" (2005). OSSA Conference Archive. 65.

https://scholar.uwindsor.ca/ossaarchive/OSSA6/papers/65

This Paper is brought to you for free and open access by the Conferences and Conference Proceedings at Scholarship at UWindsor. It has been accepted for inclusion in OSSA Conference Archive by an authorized conference organizer of Scholarship at UWindsor. For more information, please contact scholarship@uwindsor.ca. 


\title{
Warranting Arguments, the Virtue of Verb
}

\author{
JAMES F. KLUMPP \\ Department of Communication \\ University of Maryland \\ College Park MD 20742-7635 \\ USA \\ jklumpp@umd.edu
}

\begin{abstract}
The Uses of Argument presented Stephen Toulmin's call for a working logic and the classical statement of his layout of argument. In chapter 3, which explicated the model, each element was defined using multiple strategies. Toulmin presented his terminology both as a category system for labeling statements or propositions and as a functional vocabulary to describe 'what . . . is involved in establishing conclusions by the production of arguments' (97). These two uses of the vocabulary did not come together seamlessly in his account, however. Nor have they done so in subsequent work. Interpretations and elaborations of the Toulmin model, including Toulmin's own with Rieke and Janek in An Introduction to Reasoning, have tended to characterize the overall model functionally but have defined and illustrated the elements as different kinds of statements. This paper calls for more attention to a definition for the 'warrant' element that emerges from the dialogue strategy of definition: 'to warrant' as a verb capturing the movement between the data and the claim. The paper argues that the result of this perspective is a more rhetorically based statement of the Toulmin model.
\end{abstract}

KEY WORDS: Toulmin, warrant, argument, working logic

In the opening paragraphs of The Uses of Argument (1964), Stephen Toulmin commits himself to understanding 'the canons and methods we use when, in everyday life, we actually assess the soundness, strength and conclusiveness of arguments' (1). There are a number of interesting if not novel elements entailed in this commitment. At its heart is an assertion that one of the elements of day-to-day language use is the assessment of argument. The dimensions of this assessment are designated soundness, strength and conclusiveness. Furthermore, the raising of the issue of how we actually assess arguments gives the reader the hint of the differentiation Toulmin will introduce between the idealized logic of traditional perspectives and his effort to study working logic: reasoning as it takes place in 'everyday life.' Finally, the commitment posits a discernible system of assessment knowable through the study of people arguing.

Toulmin's commitment in those opening paragraphs first 
attracted me to his ideas (when the book sold for \$1.95). As a student of rhetorical argument - the ways in which people draw upon the resources of language to understand their world and cajole each other to cooperative participation in that endeavor - I found that Toulmin's task captured my own. Indeed, in my home discipline of speech communication Toulmin became the standard introduction to microargument.

If a layout of argument is to aid the description and assessment of argument, then its terms and characteristic moves must permit the casting of the argument that surrounds us every day into its framework. Those like me who are rhetorical critics must be able to draw upon the layout to open up the strategic dimensions of argument. More to the point, everyday users - notably our students - must be able to develop their abilities with a use of the layout on the fly, as it were. Over the years, the Toulmin layout has been modestly successful at these tasks. Occasionally, the layout has been employed in laying out arguments for analysis, but it cannot be said to have captured totally the market of rhetorical critics. While the use of the layout in textbooks in argumentation and even in public speaking is near total, those with whom I converse about the subject and those I supervise in my department's courses in argumentation report that their students suffer great difficulty in casting argumentative exchanges within the layout. 'Is this statement data or a warrant?' is still guaranteed to glaze eyes. In fact, it is that move - the obligation to recast uttered statements into an expressive form complying with the linguistic characteristics of data or warrant - that diminishes the utility of the layout.

Many years ago, in rereading The Uses of Argument, I was struck by the novelty of his first definition of the terms of the layout: a conversation between two interlocutors built around the claims of the first and the skeptical challenges of the second. I observed that seldom was this schema employed when teaching the Toulmin layout or conceptualizing argument with its terminology. I committed to doing so. The result has been a profoundly more useful layout that focuses on the act of arguing rather than the propositional form of premises.

My task today is to explicate this approach to the layout. I argue that the key to this interpretation is to recognize that 'to warrant' is a splendid English verb that perfectly captures the dynamic movement of reasoning in the Toulmin layout. I will argue that the reconceptualization of argument embodied in the Toulmin model reaches its full potential to move from a idealized to a working logic when the requirement to cast arguments into propositions is also left behind and the layout deployed as a method of portraying the underlying movement of reasoning. Thus, presenting the key term of the layout - the warrant - as a verb, the part of speech capturing movement, best actualizes the working logic.

\section{TO WARRANT AN ARGUMENT}

In the essay he calls 'The Layout of Arguments' Toulmin offers at least seven strategies for defining 'warrant.' These various strategies do not leave inconsistency in their wake, but if one seeks to fully appreciate the difference between the new working logic that Toulmin championed and the geometrically based logics that he sought to displace, certain definitions emerge as more effective in assisting the 'man-in-the-street' to achieve 'application to his practice' (1).

Some of these definitions link the concept of warrant with the major or middle premise of traditional syllogisms. Following a reprisal of the famous syllogism establishing Socrates' mortality, Toulmin works toward a similar argument about the Swede Petersen's 
Protestantism (108-10). He is exploring the differences in expression in arguments in which the backing replaces stated warrants. In case we miss the link to syllogistic logic he proffers: 'The relevance of our distinction to the traditional conception of 'formal validity' should already be becoming apparent' (110). We do not, of course, want to lose sight of the purpose of the strategy on these pages: drawing upon the syllogistic analogy permits the clearest statement of the distinction between the syllogistic or analytic argument and substantial argument. In this example Toulmin is making the point that in everyday discourse it is most often the backing to the warrant that is stated, not the warrant itself.

Unfortunately to my mind, Toulmin like Sisyphus loses much of the uniqueness of a working logic the farther he goes toward developing this example. His rather awkward prose rendering of the argument translates easily into his layout, but at the price of insight into the generalization of his procedure to natural prose expressions. The same problem continues as universal premises are explored in observations about our club-footed friend Jack (113-18). Taken together with the next section, which draws together arguments about the Bermudan Harry and Jack's sister Anne's red hair to make the distinction between substantial and analytic arguments (118-24), Toulmin's treatment returns the effort at distinction to the old strategic problem of casting arguments into proper expressive form as an avenue toward testing their logical validity. Thus, the search for a working logic returns to the characteristic moves of the idealized logic. This confusion has led many to see Toulmin's model as less than novel, or as Brockriede and Ehninger (1960) put it as 'a syllogism lying on its side' (47).

A second definitional strategy exploits a different analogy - the law courts. Toulmin compares the warrant to points of law. 'This distinction, between data and warrants, is similar to the distinction drawn in the law-courts between questions of fact and questions of law, and the legal distinction is indeed a special case of the more general one - we may argue, for instance, that a man whom we know to have been born in Bermuda is presumably a British subject, simply because the relevant laws give us a warrant to draw this conclusion' (100). In the end, this statement dissolves the analogy into an argument by division. The important confusion to $m e$ is that the argument's reference to the power of relevant laws to supply a warrant, combined with the specific to more general reasoning (or vice versa), leaves behind the impression of warrants as formal statements of relationship contextualized within general principles.

Although I find this characteristic unfortunate, Toulmin does not. Although he repeatedly makes the point that in working logic 'data are appealed to explicitly, warrants implicitly' (100), he often offers warrants in propositional form. In the analogy to the law, the reference is to positive or written law. There are, in the law books, written specifications that are (in the force of this statement of the analogy) the implicit warrants of the argument.

Having this point fresh in our minds, it is a propitious time to introduce a distinction that sorts Toulmin's strategies for me. In the two strategies we have just considered, warrants are propositional. They have substance which they lend to the argument. Is the propositional nature of legal statutes a characteristic shared by their special character and the general character of warrants, or does the propositional character represent a dimension of what makes them special? In fact, read in context what makes them special is that they are part of the field of law. Thus, we are led to believe that all warrants have tacit, but fundamental, propositional character. Shortly I will suggest that other 
definitional strategies release us from this propositional form to emphasize, in preference to their propositional quality, the power of warrants to authorize the movement from data to claim.

Perhaps the propositional definitions reach their most troubling manifestation in a third strategy of definition: 'general, hypothetical statements, which can act as bridges, and authorise the sort of step to which our particular argument commits us. These may normally be written very briefly (in the form 'If D, then C')' (98). Despite the fact that Toulmin goes on to complicate this propositional expression, the simple statement of hypothetical - if D, then C - is too often taken to be the field-invariant propositional form of a warrant, the propositional content only being field-

dependent. Today I encounter teachers adopting this simple definition of warrants and encouraging students that warrants are as simple as stating: if $\mathrm{D}$, then $\mathrm{C}$. This, of course, trivializes the function of warrants. As a working logic it makes it easy to state warrants for arguments, but leaves us without what Toulmin points to as the problem required to move beyond the trivial case: the requirement that the hypotheticals be authenticated.

It is the search for authentication that takes us away from the propositional statements, for now the emphasis shifts from the form of the proposition to its function. The fourth strategy of definition is transitional: "warrants . . . correspond to the practical standards or canons of argument' (98). There is, of course, considerable difference between 'canons' and 'practical standards.' The former imply a refined sort of knowledge in which contemplation and careful sorting elevate certain propositions to a level of acceptance that others do not receive. Canons are socially authorized in an extended process of refinement. Practical standards seem to receive their status through a more commonly enacted day-to-day refinement of experience.

The movement to practical standards I take as a significant move. For Toulmin with this simple move carries us from a formal refinement by experts, perhaps even by idealized logicians, into a socially functioning everyday practical activity in which normal blokes acquire a practical knowledge of what data warrants important claims. In this pair Toulmin gives us our first glimpse of his later distinction between warrant-using and warrant-establishing arguments. Warrants have become the product of socially constructed argumentative processes - formal and informal. The conjunction Toulmin has constructed portrays the broad assertion that the social processes of warrant husbandry mark scientific and other academic disciplines, the law, and ordinary day-to-day interaction. Practicality drives canonized and non-canonized reasoning.

This ambiguous functionality also marks the fifth definition of warrant: 'propositions of a . . . kind: rules, principles, inferencelicences, or what you will' (98). Rules suggest the kind of carefully performed sifting that canons of argument suggests. Principles transcend the process of canonization, seemingly signifying products that have attained a status generally recognized. The more infrequently encountered term 'inference-licences' expresses the full functional perspective on the warrant. Licenses convey the attained authority, in this case the authority of data to establish claims. The warrants remain propositions, but they now become warrants not by virtue of their form but by virtue of their power, their authority. The imprecision of the last phrase in Toulmin's definition - 'or what you will' - indicates more clearly that this list of terms communicates not the status of the propositions but their function to authorize the move from data to claim.

This move to the functional becomes explicit in a sixth 
definition of warrant. Toulmin observes: 'The question will be asked, how absolute is this distinction between data, on the one hand, and warrants, on the other.' The problem he posits is the bane of those trying to teach ordinary arguers - read students - to differentiate propositions that are claims, from those that are data, from those that are warrants. He answers: 'By grammatical tests alone, the distinction may appear far from absolute, and the same English sentence may serve a double function: it may be uttered, that is, in one situation to convey a piece of information, in another to authorise a step in an argument, and even perhaps in some contexts to do both these things at once' (99). Here is the ultimate problem of sorting propositions into the layout and what ultimately differentiates the layout and its working logic from idealized logic. The form of the sentence does not permit the separation. You cannot simply look at a sentence and tell the function it is serving. Gone are the possibilities of readily seeing the form 'if $\mathrm{D}$, then C' and saying, 'Aha! a warrant.' Propositions are warrants as they perform the function of warrants, as they authorize the taking of data as proof of a claim. They turn the pedagogic attention from teaching students to recognize the form of statements to recognizing the way in which statements function in the generation of faith in a claim.

In my judgment, Toulmin's seventh strategy (and, by the way, the earliest strategy presented in the essay) is the most fruitful in teaching the layout of argument. This is the conversation, the narrative of accomplished argument. I quote at length:

Let it be supposed that we make an assertion, and commit ourselves thereby to the claim which any assertion necessarily involves. If this claim is challenged, we must be able to establish it - that is, make it good, and show that it was justifiable. How is this to be done? Unless the assertion was made quite wildly and irresponsibly, we shall normally have some facts to which we can point in its support: if the claim is challenged, it is up to us to appeal to these facts, and present them as the foundation upon which our claim is based. . . .

We already have, therefore, one distinction to start with: between the claim or conclusion whose merits we are seeking to establish (C) and the facts we appeal to as a foundation for the claim - what I shall refer to as our data (D). If our challenger's question is, 'What have you got to go on?', producing the data or information on which the claim is based may serve to answer him; but this is only one of the ways in which our conclusion may be challenged. Even after we have produced our data, we may find ourselves again asked further questions of another kind. We may now be required not to add factual information to that which we have already provided, but rather to indicate the bearing on our conclusion of the data already produced. Colloquially, the question may now be, not 'What have you got to go on?', but 'How do you get there?'. To present a particular set of data as the basis for some specified conclusion commits us to a certain step; and the question is now one about the nature and justification of this step. (97-98)

Toulmin has posited the archetypal case of argument as a conversation in which an interlocutor challenges the grounds of our making a claim. The challenges are of different types because the questions asked are different questions. One seeks information, the other expresses the skepticism that the information provided satisfies the demand for support for the claim. By casting the process in the form of a conversation rather than in the form of propositional layout Toulmin has refocused our attention on the function our statements serve in arguing.

I now reach the edge of Toulmin's treatment in 'The Layout of Arguments' and go further than he goes. I ask: Why should the 
response to this second question be labeled 'warrant'? The answer is found in the English verb, 'to warrant': 'to provide adequate grounds for; justify; to grant authorization or sanction to (someone); authorize or empower' (American Heritage Dictionary). The question, rephrased in our terminology becomes: How does that data warrant that claim?

The verb form removes even the last vestiges of the requirement that the form of the warrant be propositional. The functional is the essence. To be sure, propositional statements may be generated to satisfy the warrant challenge, but the warrant function is the relationship between the data and the claim: the authorization of the step.

\section{WARRANTING AS A WORKING LOGIC}

The functional emphasis transforms the warranting concept into the synthetic heart of the working logic. To the arguer, the key choice is the selection of information (data) to support (warrant) the claim. The geometry of the argument becomes linear, but linear with multiple and complex vectors. Arguments emerge out of the assertions and challenges as interlocutors negotiate the warranting of the claim. Warranting challenges may be met by the selection of alternative information (data), by the assertion of the authority of the information to prove the claim (backing), or by the generation of chained arguments in which the arguer makes claims about the relationships of data and claim - in Toulmin's terms warrant-establishing arguments. The dialectic that marks the skeptical relationship of the interlocutors is the search for data that warrants the claim. When the strength of the warranting relationship is successfully challenged, the options of identifying special limiting conditions (rebuttal) and recognizing the shading of probabilities (qualifiers) provide other options for the arguer negotiating the strength of his/her argument with the interlocutor.

The functional emphasis also expands the scope of argument by placing the individual microargument into a judgment contextualized beyond its own terms. This expansion results from the idea that the warranting power of data transcends the individual argument. An arguer selects data that $\mathrm{s} /$ he anticipates will warrant the claim. That power - that authority - lies in the complex warrant-establishing process. The licensing quality of warrants that Toulmin describes grows from the transcendent, socially constructed, authority of a field. The social complex that makes arguments go has the sensitivity to the warranting power of information at its heart.

The power of warrants thus lies at the intersection of two dimensions: the pragmatic and the social. A working logic is the product of argumentative language acts that refine and work through a kind of Darwinian testing of the quality of warrants. Warrants that lead to faulty decisions - decisions that lead to unwise actions - have their authority eroded in their pragmatic use. Warrants that show wisdom have their authority reinforced. This evaluation is carried in the social knowledge that resides in the field of the interlocutors.

In describing this central role for warrants, we have touched on the major elements that set Toulmin's working logic apart from idealized logic: the secondary triad, the idea of warrant-using and warrant-establishing arguments, the context of fields as active elements of argument. So the functional definitions carry the virtues of Toulmin's critique. The synthetic power of functional definitions captures the multiple dimensions that shape an argument in the Toulmin system. 
I began this exploration of a functional view of warrant with a very pragmatic diagnosis of the Toulmin model: my students could not readily analyze an argument, discuss its working with the Toulmin terminology, then think through its weaknesses, measurably better than they could with other ways of treating argument. Nor was the terminology particularly dominant as a language for rhetorical critics who are so often interested in argument. 1 So I return now to a bald claim: my students work more easily with a functional notion of warrants, and I find the synthetic character of the functional definitions much more conducive to the full understanding of argumentative complexes.

I cannot generate any systematic data to support my claim for the students' ease of use, but I can report my long experience in the classroom. Furthermore, I think I understand why the process is so much easier. First, the most difficult process in logical analysis for students is the process of turning normal English sentences into propositional form. In the functional deployment of the layout, they do not need to do so. They simply need to understand the three functions at the heart of the model: claiming, supporting, and warranting. What is your claim? What data will you offer to support it? Why do you think that data warrants that claim? Consider a simple and actual example:

Bonnie: I am afraid you will not be able to graduate in May. Jeremy: Why not?

Bonnie: You failed to file the Application for Diploma form by the February deadline. paperwork?

Jeremy: I thought they were fairly lenient with deadlines on this

Bonnie: Generally they are, but not with that form. Long experience tells us that is the one deadline you better not miss.

No need to work through translation problems here. Bonnie's claim is clear. She is shown responding to Jeremy's doubt with a fact explaining his problem. His effort to doubt the authority of her fact to warrant her claim is met with a sophisticated response: backing and rebuttal.

No doubt part of the secret here is the conversational model. In deciding the strategy to present this view of argument, I pondered whether the proper stress was on the warrant as a verb or on the conversation as a paradigm case of argument. Toulmin's standard conversation and the specific variations on it present the interplay of assertion and skeptical challenge that constitutes the dialectic of argument. The conversation stresses that the notion of 'making an argument' as the expressive assertion of a single arguer oversimplifies the more subtle calculation of interactional awareness that we stress in talking about rhetorical argument. Indeed, one message I often deliver to students terrified about the possibility of debate, where an interlocutor could actually tell them their argument was not convincing, is that the debater is the lucky one: she knows where her interlocutor's resistance is. The public speaker must arrive at the issues of resistance in the face of silence.

I am mindful, of course, that insisting that translation into a conversation be substituted for translation into propositions is still a translation into a form with the attendant difficulties. Even though I believe that conversational form is a more natural form for a working logic, I believe the conversational model teaches differently than the propositional. The conversational model is a pedagogic strategy for 
teaching the interactive function of claim, data, and warrant. That lesson learned, the analysis of individual arguments ought to feature an appreciation for the functioning of the argument without translation into conversational form. In propositional analysis, on the other hand, translation into propositions is a necessary step. Indeed, the probative power of propositional analysis lies in the translation into propositions. It is translating the stuff of argument into propositional form that allows formal assessment to proceed. $\stackrel{2}{2}$ Thus, I believe that the essential lesson I wish to teach ordinary arguers is the functional relationships in argument, not the conversational form.

Furthermore, although the conversational form may more directly record many cases of working logic, other cases are in other forms. A few paragraphs ago I highlighted my claim that students found the functional approach easier to employ. I acknowledged a characteristic of the field as I anticipated the interlocutor's expectation that I might produce systematic evidence of this greater ease. But I rejected that strategy for warranting my claim, asserting instead the rather vague authority of my experience. Indeed, this is an argument where the backing is explicit and the data implicit in the argument. In re-presenting that argument I have not cast it into the conversational form (although I have used that metaphor a bit in describing my strategic choices). I have instead featured the ways the various statements of the argument relate functionally to each other in producing my argumentative effect.

Still another advantage my students demonstrate in learning the model functionally is their greater ability to think through the options defined by the central role of the warrant as a synthetic pivot of assertion and challenge. When the authority of warranting is challenged, they can see the catalog of moves open to the arguer. They develop a feel for the nature of the challenge and the appropriateness of alternative data, backing, rebuttal, qualification, or chain argument.

The centrality of warranting in the functional definition also facilitates my students' ability to use the model in assessment. They quickly perceive the context of the argument in a field. The social test Is that the data that warrants that sort of claim in that field? - comes more naturally as a question. But once that question is asked, the question turns to: Why not? If not, how might the claim be warranted? What are the restrictions of the field? How does that field establish warrants? Are there possibilities to strengthen the argument? This fundamental distinction between idealized logic and working logic becomes a plausible way of thinking through arguments.

The result for me is a more consistent pedagogy of argument. Students work more easily with the ultimate questions of perceiving, testing, challenging, and strengthening arguments. But they also perceive argument as a fundamental language activity through which humans negotiate their daily lives.

I also asserted that to a rhetorical critic like me the synthetic power of warranting arguments permitted a fuller vocabulary for dealing with the texture of argument. I would point to some past and forthcoming work on the Bush administration's arguments for the Iraqi war as illustrative (Klumpp). I would also call attention to the recent drama in the United States over the fate of Terry Schiavo. The loud and splintering texture of public argument over the fate of this unfortunate woman and its implications for fundamental issues of life and death opens in so many ways to a rich consideration of issues of warranting. The contrast of argument in the legal field to argument in the streets; the technical involvement of Congressional action; the role of the field of medicine versus the human connection of a mother and father; differences in the acceptable evidence of meaningful life; all of the 
bypassing that constitutes the differing positions on these issues take on apparent texture as the intersection of various fields of argument and the warranting practices that define each. While the constraints of this essay do not permit a full elaboration of this episode, consider only the bypassing over the question of Terry Schiavo's responsiveness to those around her. The legal system relies on the diagnosis of medical experts to warrant its conclusion that Schiavo exists in a 'persistent vegetative state.' The medical profession has specific criteria for such a state, and telemetry and specific diagnostic techniques provide data to experts trained in medicine with which they warrant their claim. The streets see instead a videotape of Schiavo with eyes aimed in the direction of the disembodied voice of her mother. Connectedness is perceived in the image constituting the human responsiveness that parents perceive in their children as love. Clearly these are two different fields. The latter does not constitute evidence for the court, nor is medical testimony relevant to the street. Indeed, an interesting moment occurs when Senator Bill Frist, Senate majority leader and a trained and licensed physician, attempts to bridge these fields by asserting his medical credentials and claiming diagnosis via the videotape. His statement is met with doubts about medical personnel who would diagnose via videotape. Clearly the issues of what warrants claims of human responsiveness and the contrasting contexts of fields accepting claims only by their own acceptable warranting help to define the bypassing that marks the conflict between the courts and the streets.

\section{A FINAL THOUGHT}

I have not asked Toulmin why he chose the term 'warrant' for this element of the pentad. And to the best of my reading he never explains the choice in Uses. The most common definition of the noun 'warrant' points to the legal document issued by a court authorizing action by the court's officials. That kind of image of formal proceedings to authorize action distorts the more informal sense of appropriateness captured in a working logic. To me, the more straightforward definition of 'to warrant' - 'to provide adequate grounds for; justify; to grant authorization or sanction to (someone); authorize or empower' - better achieves the distinctiveness of a working logic. I propose a change of emphasis, a tilting from one definitional strategy in 'The Layout of Arguments' to another. I frankly admit that I propose an elaboration toward rhetorical argument with its focus on explaining the argumentative workings of everyday arguers and away from the validity concerns of logicians. Thus, I urge diminished urgency for the search for the propositional linkages of data to claim. Instead, I believe that a greater concern for the functional relationships that define the layout of argument promises a more vital approach to the working logic that Toulmin and I seek.

\section{REFERENCES}

Bates, Benjamin R., John A. Lynch, Jennifer L. Bevan, and Celeste M. Condit: 2005. 'Warranted Concerns, Warranted Outlooks: a Focus Group Study of Public Understandings of Genetic Research.' Social Science and Medicine 60, 33144.

Brockriede, Wayne, and Douglas Ehninger: 1960. 'Toulmin on Argument: An Interpretation and Application.' Quarterly Journal of Speech 46, 44-53.

Klumpp, James F.: in press. 'The Three Arguments of Iraq.' Proceedings of the NCA/AFA Summer Conference on Argumentation. National Communication Association, Washington. 
McKerrow, Raymie: 1990. 'The Centrality of Justification: Principles of Warranted Assertability.' in David Cratis Williams and Michael David Hazen (eds.), Argumentation Theory and the Rhetoric of Assent, Tuscaloosa, Univ. of Alabama Press.

Simosi, Maria: 2003. 'Using Toulmin's Framework for the Analysis of Everyday Argumentation: Some Methodological Considerations.' Argumentation 17 185-2003.

Toulmin, Stephen Edelston: 1964. The Uses of Argument. Cambridge University Press, Cambridge.

Toulmin, Stephen, Richard Rieke, and Allan Janik: 1984. An Introduction to Reasoning, $2^{\text {nd }}$ edition, Macmillian, New York.

Willard, Charles Arthur: 1976. 'On the Utility of Descriptive Diagrams for the Analysis and Criticism of Arguments.' Communication Monographs 43, 308-19.

1 There are exceptions that employ the verb form to great insight. See, for example, McKerrow (1990); Simosi (2003); Bates et al. (2005). Although all these employ the notion of warranting claims with data, they generally do not exploit the visual layout in doing so.

2 Charles Arthur Willard (1976) argues that translation is endemic to diagrammatic strategies for treating arguments and that translation into propositional form is the essence of Toulmin's argument. 